\title{
The Difference Scores of Positive and Negative Syndrome Scale Exited Components in Psychotic Agitation Patients of Haloperidol Injection and those Prescribed with the Injection of Haloperidol and Diazepam
}

\author{
Muhammad Affandi ${ }^{*}$, Elmeida Effendy, Bahagia Loebis, Muhammad Surya Husada, Nazli Mahdinasari Nasution \\ Department of Psychiatry, Faculty of Medicine, University of Sumatera Utara, Medan, Indonesia
}

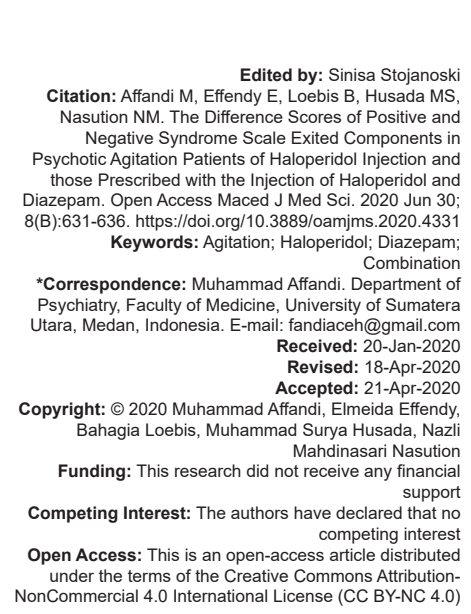

Introduction

The psychotic agitation procedural treatments must have been based on the principle of unrestrained practices to avoid human rights violations [1]. The restraining and isolation occasionally cannot be avoided due to their aggressiveness which is a common phenomenon due to the discontinuation of drugs consumptions [2]. In several cases, agitation can be controlled by non-pharmacological approach, such as verbal interventions and de-escalation; however, some individuals require pharmacological medications [3].

More than a half century, various pharmacological drugs and treatments to control agitation behaviors have been tested. At present, the most common psychotic medications are the first and second generation of antipsychotic (FGA) medications, and benzodiazepine, even the second-generation combinations are favored in treating agitation patients [4]. The FGA, which, in this case, is haloperidol, has been extensively used in a very long time in the treatments of psychotic agitation. The combination of antipsychotic drugs and benzodiazepine requires varied mechanisms by expecting augmentation process as well as avoiding complications due to high dosages of antipsychotic. The amnesic effects of benzodiazepine benefits to patients who have been suffering by tragic moments such as frequent medications, restraining, and isolation. Favorable combination in oral treatments is haloperidol (with the addition of procyclidine) and diazepam, whereas intramuscular treatments were performed by injecting haloperidol (with procyclidine) and lorazepam [6].

Haloperidol is an antagonist receptor of dopamine-2 which has minimal effects to vital sign, anticholinergic activities, antihistamine, and low interactions to any non-psychotic drugs. The side effects are extrapyramidal symptoms (EPSs) such as parkinsonism, dystonia, and akathisia, which can be treated by anticholinergicmedications(diphenhydramine and benztropine), QTc prolongation-torsade de pointes (Tdp), particularly for intravenous injections, neuroleptic malignant syndrome, and catatonic reaction specifically in high dosages prescription [5], [6]. 
Meanwhile, benzodiazepine drugs which are commonly prescribed in treating psychotic agitation are diazepam, lorazepam, clonazepam [6], and midazolam [7], [8]. Midazolam has higher superiority than that in haloperidol in controlling agitation, however, it is extremely sedative which is sleep-inducing effects. The clonazepam has limited efficacies in handling agitation so that it is not recommended. Lorazepam is benzodiazepine group which is favored in the treatment of agitation; however, in Indonesia, parenteral formulation is not available [7], [8], [9], [10].

A study conducted by Canon, in 2001, which involved 116 emergency units in Australia has reported that the common prescribed therapies were haloperidol (93\%), midazolam (82\%), and diazepam (59\%). The same study also found that the prescription of benzodiazepine and one tranquilizer at least occurred in $97 \%$ of emergency units [11]. The prescription of intramuscular diazepam treatments is not considerably explored in clinical studies. This is probably due to the difficulties in pharmacokinetic issues related to its gluteal injections. However, no difficulties have been reported during the injection of IM deltoid, in which the absorption is quicker than that in IM gluteal [12] Divoll et al., in 1983, have reported that the diazepam absorption was performed in a quick and complete way compared to those in IM deltoid injections [13], [14].

According to the Indonesian National Formularium, diazepam and midazolam must be available in primary and referral health-care facilities, while the oral lorazepam drugs availability is merely preserved by referral hospital. Nevertheless, the preservation of diazepam should have been in higher quantities in all health-care facilities. Due to the haloperidol and diazepam availability is sufficient which also has more affordable prices compared to the second generation of antipsychotic (unavailable of ampoule), a study is conducted to determine score differences in Positive and Negative Syndrome Scale (PANSS-EC) assessment [15] of psychotic agitation patients who have been prescribed by haloperidol and diazepam injections and only haloperidol injections.

\section{Materials and Methods}

\section{Research design}

This study is an open trial experimental study with pre- and post-test. The population is agitation psychotic patients who have visited the emergency unit of mental hospital of Prof. Dr. M. Ildrem, North Sumatera Province in the period of June 2019-September 2019. The samples collection was performed throughout non-probability sampling type with consecutive sampling. Due to limited reports regarding Indonesian patients, a preliminary study by recruiting 20 subjects divided into two groups, in which the number of study samples was obtained and was performed. Based on a previous study [16], with average deviations which were classified significant results for $n=3,32$ subjects were recruited for every groups (the first group was injected by haloperidol with the addition of diazepam, while the other group was prescribed only by the injection of haloperidol). This study has been agreed by the Research Ethical Committee of Medical Faculty of Universitas Sumatera Utara, Indonesia (No. 664/TGL/ KEPK FK USU-RSUP HAM/2019) which follows the Nuremberg Code and Helsinki Declaration.

\section{Research subjects}

The inclusion criteria in this study were male agitation psychotic patients (with PANSS-EC score for $\geq 14$ with subitem assessment score for $\geq 4$ ), with the age of 18-40 years of old and normal body mass index (BMI). Meanwhile, the exclusion criteria were the patients who have been experiencing normal medical disorder and those who have drugs and alcohol abuse (except caffeine and nicotine) [17], [18], [19], [20], [21], [22].

\section{Research procedure}

Recruited subjects have followed the inclusion and exclusion criteria (with PANSS-EC baseline score assessment, body mass, and height measurements). Then, random allocation by following coins flipping was performed so that every subject had exact opportunity to be involved in the study. Next, medication injections were performed based on random groups; (1) First group: $5 \mathrm{mg}$ of haloperidol, IM, in medius/lateral musculus gluteus and the injections of $10 \mathrm{mg}$ of diazepam, IM, in the deltoids musculus which is located on a third part of hands, and (2) Second group: $5 \mathrm{mg}$ of injection, IM, medius/lateral musculus. During the injections, subjects that were agitated were restrained and isolated. Afterward, PANSS-EC assessments were carried out in 30 and $60 \mathrm{~min}$, and calmed patients were carried out to the wards. The syndrome extrapyramidal side effects were examined by performing standard procedures in detecting the syndrome by the time of PANSS-EC assessment, in which confirmed syndromes in patients were injected by $10 \mathrm{mg}$ of diphenhydramine and were excluded from the study. As this study was performed under on treatment analysis, excluded subjects were replaced by others [23].

In PANSS-EC assessment, suitability tests among researchers and interpreters were conducted. The analysis tests utilized numeric comparative tests (Bland Altman) due to numeric variable of scales that were measured. The results of analysis tests showed that limit of agreement was in 5 and $5(-2.38-2.10)$. Therefore, it can be concluded that among observers, acceptable suitability/reliability was confirmed [24]. 


\section{Statistical data analysis}

The data analysis was carried out using the Statistical Package for the Social Sciences software. The design of this study is numeric comparative measurements with unpaired groups, so normal data distribution was proceeded throughout general linear model + post hoc tests. However, abnormal data distribution was analyzed using Mann-Whitney, corrected repetition tests were performed. Normality data tests were conducted using Shapiro-Wilk tests since $<50$ samples were collected.

\section{Results}

Table 1 highlights categorical and numerical data. The categorical variables which are discussed are educations, occupations, and marital status, in which all of these three variables had categorical analytical comparative diagnosis with unpaired table of $2 \times 2$. From the test analysis which was performed, $<5$ or $20 \%$ of expected count value was obtained so that Chisquare test requirements were befitted. Subsequently, for table of $2 \times 2$, a suggested analysis was Chi-square with continuity correction. From the test analysis which was carried out, no confirmed significant difference of demographical characteristics in terms of educations ( $p>0.439)$, occupations $(p<0.784)$, and marital status $(p<0.281)$ was found [23], [24]. From Table 1, it can be seen that the highest percentages of educations, occupations, and marital status were in primary and junior high school (62.5\%), unemployment $(70.3 \%)$, and non-marital status $(68.7 \%)$, respectively.

Table 1: Demographical characteristics of psychotic agitation patients for both groups

\begin{tabular}{|c|c|c|c|c|}
\hline Variables & $\mathrm{n}(\%)$ & $\begin{array}{l}\text { Group I } \\
\text { (haloperidol+diazepam) }\end{array}$ & $\begin{array}{l}\text { Group II } \\
\text { (haloperidol) }\end{array}$ & $p$ \\
\hline Ages (years) & & $32.5(25.0-40.0)$ & 36.0 & $0.102^{*}$ \\
\hline Median (min-max) & & & $(25.0-40.0)$ & \\
\hline \multicolumn{5}{|l|}{ Educations primary } \\
\hline Junior high & $40.0(62.5)$ & $22.0(55.0)$ & $18.0(45.0)$ & $0.439^{\star *}$ \\
\hline 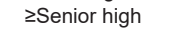 & $24.0(37.5)$ & $10.0(41.7)$ & $14.0(58.3)$ & \\
\hline \multicolumn{5}{|l|}{ Occupation } \\
\hline Working & $19.0(29.6)$ & $9.0(47.4)$ & $10.0(52.6)$ & $0.784^{* *}$ \\
\hline Not working & $45.0(70.3)$ & $23(51.1)$ & $22(48.9)$ & \\
\hline \multicolumn{5}{|l|}{ Marital status } \\
\hline Married & $20.0(31.2)$ & $8.0(40.0)$ & $12.0(60.0)$ & $0.281^{* *}$ \\
\hline Not married & $44.0(68.7)$ & $24.0(54.5)$ & $20.0(45.5)$ & \\
\hline \multicolumn{5}{|l|}{ BMI } \\
\hline $\begin{array}{l}\text { Median } \\
(\min -\max )\end{array}$ & & $23.4(20.5-24.8)$ & $\begin{array}{l}23.4 \\
(20.5-24.8)\end{array}$ & $0.979^{*}$ \\
\hline \multicolumn{5}{|l|}{ PANSS-EC base } \\
\hline \multicolumn{5}{|l|}{ line scores } \\
\hline Mean \pm SD & & $28.7 \pm 2.8$ & $28.4 \pm 2.6$ & $0.654^{* * *}$ \\
\hline
\end{tabular}

The numerical variables that are discussed in Table 1 are ages, BMI, and baseline PANSS-EC score. These three variables involve in unpaired groups numerical analytical comparative diagnosis. The analytical tests were performed by the time the normality data test by conducting Shapiro-Wilk test due to the number of samples was done. The Shapiro-Wilk tests for these three samples showed only baseline PANSS-EC scores were distributed normally with $p>0.05$, whereas the ages and BMI were confirmed to be undistributed normal with $p<0.05$. For undistributed normal data, transformation data were conducted using log function; however, unsuccessful transformation occurred which suggested to alternative tests for every variable [23], [24]. In age and BMI variables, the Mann-Whitney U-tests were carried out, and it can be seen that no significant differences were occurred between these two variables, with $p=0.102$ and $p=0.979$, respectively.

The PANSS-EC baseline scores, in which the data were distributed normally, unpaired $t$-test ( $t$ independent sample) was performed. From the test results, Levene's variant test was $0.572(>0.05)$ so that equal variances assumed was confirmed for both groups which accounted for 0.654 with mean difference for 0.313 and IK value for $95 \%$ in between -1.075 and 1.700. Due to $p<0.05$, it can be concluded that no significant difference was found [23], [24].

Tables 2 and 3 which display Shapiro-Wilk tests to the three numerical variables show normal data distribution with $p<0.05$. Subsequently, repeated ANOVA with general linear model was conducted which was followed by post hoc pairwise comparisons (Bonferroni) analysis. The multivariate test results showed the value of significance $<0.001 \quad(<0 / 005)$, so it can be concluded that two different measurements were found in minimum. To perceive these differences, output pairwise comparisons that compared the first and second, first and third, and second and third measurements were carried out. The significance value for every comparison was $<0.001$ so that statistical conclusion can be drawn that remarkably significant decreasing of PANSS-EC score for the first group was obtained in the baseline in 30 and $60 \mathrm{~min}$. However, according to the classification that

Table 2: PANSS-EC scores of patients in Group I

\begin{tabular}{llll}
\hline PANSS-EC time & $\mathrm{n}$ & Average $( \pm \mathrm{std})$ & $\mathrm{p}$ \\
\hline Baseline & 32 & $28.72 \pm 2.86$ & $<0.001$ \\
$30 \mathrm{~min}$ & 32 & $15.97 \pm 3.60$ & \\
$60 \mathrm{~min}$ & 32 & $14.19 \pm 3.62$ & \\
\hline Repeated ANOVA tests and post hoc analysis & p<0.001. PANSS-EC: Positive and Negative Syndrome \\
Scale- Exited Components. &
\end{tabular}

has been determined in this study, minimal deviation score of PANSS-EC is considered to be significantly difference the value for 3 . In clinical term, significant decreasing of PANSS-EC scores for both baseline, since their score was $28.72 \pm 2.86-15.97 \pm 3.60$ for base line30 $\mathrm{min}$, while for baseline $60 \mathrm{~min}$ for 28.72 $\pm 2.86-14.19 \pm 3.62$. However, in this study, it is not classified as significantly difference due to the scores of PANSS-EC in 30 and 60 min which accounted for 15.97 $\pm 3.60-14.19 \pm 3.62$ [23], [24].

Table 3: PANSS-EC scores of patients in Group II

\begin{tabular}{llll}
\hline PANSS-EC time & $\mathrm{n}$ & Average $( \pm$ std $)$ & $\mathrm{p}$ \\
\hline Baseline & 32 & $28.41 \pm 2.68$ & $<0.001$ \\
$30 \mathrm{~min}$ & 32 & $20.25 \pm 3.02$ & \\
$60 \mathrm{~min}$ & 32 & $18.94 \pm 2.92$ & \\
\hline \multicolumn{4}{l}{ Repeated ANOVA tests and post hoc analysis p<0.001. PANSS-EC: Positive and Negative Syndrome } \\
Scale-Exited Components.
\end{tabular}


Table 4 of Shapiro-Wilk for three variables of three numerical data for every group displays normal data distribution with $p>0.05$. Subsequently, repeated ANOVA test with general linear model in which the results of time interaction influenced multivariate test and PANSS-EC scores contributed to significant value for $<0.001(<0.005)$. These results implied to the different decreasing of PANS-EC scores convincingly in between two groups in all assessments. The results of multivariate tests have been confirmed by the parameter estimates that were obtained from $p$ value, in which it was based on 0.654 of baseline, $<0.001$ in $30 \mathrm{~min}$, and $<0.001$ in $60 \mathrm{~min}$. The significant value of 0.654 and the confident value of $p$ from average deviation of assessment that passed the value of 0 in the baseline were not analyzed since this is a clinical study. Nevertheless, it can be concluded that a significant decreasing of PANSS-EC scores was found in both groups in 30 and $60 \mathrm{~min}$ [23], [24].

Table 4: PANSS-EC scores of samples in both groups

\begin{tabular}{lllll}
\hline $\begin{array}{l}\text { PANSS-EC } \\
\text { time }\end{array}$ & $\begin{array}{l}\text { Average } \pm \\
\text { (std) Group I }\end{array}$ & $\begin{array}{l}\text { Average } \pm \\
\text { (std) Group II }\end{array}$ & Difference (IK95\%) & $\mathrm{p}$ \\
\hline Baseline & $28.72 \pm 2.86$ & $28.41 \pm 2.68$ & $0.31(-1.08-1.7)$ & $<0.001$ \\
30 min & $15.97 \pm 3.60$ & $20.25 \pm 3.02$ & $-4.28(-5.94-2.61)$ & \\
60 min & $14.19 \pm 3.62$ & $18.94 \pm 2.92$ & $-4.75(-6.39--3.10)$ & \\
\hline PANSS-EC: Positive and Negative Syndrome Scale-Exited Components. &
\end{tabular}

\section{Discussion}

Table 1 shows that the age variable was obtained in the first group for 32.5 and 36 for the second group. For educations, occupations, and marital status variables, both groups were mainly composed of subjects with primary-junior high educations, unemployment, and non-marital status. The BMI results for both groups had exact median scores with 23.4 (minimum-maximum accounted for 20.5-24.8) and for baseline scores of PANSS-EC were $28.7 \pm 2.8$ for haloperidol and diazepam injections group, while $28.4 \pm 2.6$ for the only haloperidol group. Tables 2 and 3 show the decreasing score of PANSS-EC for both groups, in which a significant value with $p<0.001$ was obtained. Meanwhile, Table 4 displays excessive injections of haloperidol with the addition of diazepam, and it can be seen that the combination of these drugs contributed to higher value compared to that from haloperidol only.

This study is also in accordance with Pilowsky et al., in London, 1992, involved 120 subjects for $60 \mathrm{~min}$, in which onset tranquilization has been reported to have quicker effects with the addition of diazepam and haloperidol than those who consumed only diazepam or haloperidol with $p<0.03$. Significantly speaking, $19 \%$ of patients who have received intervention of a type of drug require another drugs intervention ( $p<0.03$ ), and $6 \%$ of these patients demand two additional drugs [25]. In 2016, another similar study was conducted by Korczak et al., which was a systematic review and meta-analysis in Australia for seven studies by recruiting 1135 patients experiencing quicker effects of drugs combinations within 15-20 min. The quicker sedative side effects (risk ratio $[R R]=1.31, p<0.001$ ) were experienced by the samples from combination therapy of drugs compared to those who consumed benzodiazepine, antipsychotic medications, and their combinations even though the consumptions of both therapies were in smaller dosages and frequencies $(R R=0.49, p<0.001$ dan $R R=0.64, p=0.002)$ [4].

As a comparative study, Bak et al., in 2019, have conducted a systematic review study and metaanalysis of 5353 studies with total of 17 types of drugs and 8829 subjects. This study has reported varied reduction of PANSS-EC score after $2 \mathrm{~h}$ of dosages interventions either in single or combination. PANSS-EC scores decreasing caused by lorazepam, haloperidol, haloperidol and promethazine, haloperidol and midazolam, levomepromazine, aripiprazole, olanzapine, risperidone, ziprasidone, loxapine inhalation, and placebo were 7 points, $7-8$ points, 15 points, $8-10$ points, 15 points within 90 min, 5-6 points for older subjects, $7-8$ points with one exception of smaller reduction points, 7-10 points, 7-8 points that one study has reported the decrease up to 14 points, 3-15 points, 9-11 points, and 2-6 points, respectively [8].

Based on onset of efficacy, Zun (2017) in Chicago has reported consistent agitation improvement in terms of the decreasing of PANSS-EC to be caused by combination of $10 \mathrm{mg}$ of IM olanzapine and 10-20 $\mathrm{mg}$ of IM ziprasidone for $15 \mathrm{~min}$. In contrast to 5-10 mg IM haloperidol (30-60 min), even though this was combined by $2 \mathrm{mg}$ of IM lorazepam. Nevertheless, a study has reported a decreasing in agitation within 15 min by utilizing 7.5 of IM haloperidol per day, as well as the utilization of IM aripiprazole with placebo control that has been reported to decrease PANSS-EC scores significantly within 45-60 min (initial assessments were performed in minutes of 15-30) [20].

In this study, the results obtained showed that several patients were recommended to receive reinjections by $60 \mathrm{~min}$. For haloperidol combined with diazepam, 18 individuals (56.25\%) and 27\% (84.37\%) for haloperidol only group were advised. A study conducted by Pilowsky et al. (1992), it has been reported that $19 \%$ of patients receiving one type of drug required one additional drug and two types of additional drugs for $6 \%$ of patients [25]. On the other hand, additional consumption of antipsychotic and their combination also has been reported in significantly reducing the sedative effects compared to those in benzodiazepine only $(R R=0.49, p<0.001$ and $R R=0.64, p=0.002)$ [4]. This difference could have been explained due to the average baseline score of PANSS-EC (28.72 \pm 2.86 and $28.41 \pm 2.68$ ), and field observations have shown that medical treatments were performed given that 
the patients have started agitation behaviors such as attacking and damaging.

In this study, no meaningful side effects were confirmed. Two subjects (6.25\%) experienced the extremely minimal EPS side effects so that no necessary treatments were required which were probably caused by the minimum dosages of haloperidol. Every individual displayed actual differences under the treatment of optimal dosage of antagonist receptor dopamine. As an example, several patients experienced difficulties to tolerate $1 \mathrm{mg}$ of haloperidol side effects, whereas the others tolerated $50 \mathrm{mg}$ of haloperidol without experiencing the side effects. Determining the perfect dosages for antagonist receptor dopamine is essentially required, however, it is challenging [26]. While, several studies have reported a few side effects, including respiratory complication in 2 subjects $(2 \%)$ and cardiovascular conditions for 3 subjects (3\%). Respiration condition occurred to the flow of $60 \mathrm{mg}$ of haloperidol and $80 \mathrm{mg}$ of diazepam into bolus intravenous, in which haloperidol side effects have been reported to be EPS in $6-55 \%$ of cases, acute dystonia for $0-17 \%$ of cases, and akathisia for $8-46 \%$ of cases [25]. The side effects in cardiovascular condition have been reported to be QT elongation which can increase the risks of arrhythmia, caused by haloperidol for $0-6 \%$ of cases and lorazepam for $7 \%$ of cases, while in the use of benzodiazepine, no side effects were found [25]. However, hypotension side effects have been reported for $0-17 \%$ due to the consumption of haloperidol [8].

Although studies have been performed as open trial conditions including randomized controlled trials, no confirmed evidences as well as placebo can be considered as a gold standard in terms of effectiveness and safety of drugs types. The decision of determining and administering the antipsychotics is the authority of the doctors-patients [18], [27], [28]. This study is the first clinical study involving agitation patients in North Sumatera, and not dropout patients were obtained. As this study was carried out in an open trial without multicenter investigation which observed within $1 \mathrm{~h}$ only, further investigation in multicenter as well as various time is required to be conducted in future [29], [30], [31].

\section{Conclusions}

Based on age homogeneity, educations, occupations, marital status, BMI, and baseline PANSS-EC scores, the combination therapy of haloperidol and diazepam showed more promising results compared to those who only prescribed by haloperidol in the treatments of psychotic agitation patients. Moreover, no significant side effects were observed which indicated no further and necessary treatments due to lower dosages of combined antipsychotics.

\section{References}

1. Winters L, Eaton J. Emergency treatment of the acutely disturbed and aggressive patient. In: Thara R, Vijayakumar L, editors. Emergency in Psychiatry in Low and Middle-income Countries. $2^{\text {nd }}$ ed. New York, London: Routledge, Taylor and Francis Group; 2017. p. 44-53.

2. Volicer L, Citrome L, Volavka J. Measurement of Agitation and Aggression in Adult and Aged Neuropsychiatric Patien: Review of Definitions and Frequently Used Measurement Scales. Cambridge, United Kingdom: CNS Spectrumus, Cambridge University Press; 2017. p. 1-8. https://doi.org/10.1017/ s1092852917000050

3. Zeller SL, Citrome L. Managing agitation associated with schizophrenia and bipolar disorder in the emergency setting. Western J Emerg Med. 2016;17(2):165-72. https://doi. org/10.5811/westjem.2015.12.28763

PMid:26973742

4. Korczak V, Kirby A, Gunja N. Chemical agent for the sedation of agitated patient in the ED: A systematic review. Am J Emerg Med. 2016;34(12):2426-31. https://doi.org/10.1016/j. ajem.2016.09.025

PMid:27707527

5. Haverkampf J. Psychiatric emergencies, communication and medication: Agitation. J Psychiatry Psychother Commun. 2017;6(4):96-100.

6. Cookson J. Rapid tranquillisation: The science and advice. BJPsych Adv. 2018;(24):346-58. https://doi.org/10.1192/ bja.2018.25

7. Klein LR, Driver BE, Miner JR, Martel ML, Hessel M, Collins JD. Intramuscular midazolam, olanzapine, ziprasidone, or haloperidol for treating acute agitation in the emergency departement. Ann Emerg Med. 2018;72(4):374-385. https://doi. org/10.1016/j.annemergmed.2018.04.027 PMid:29885904

8. Bak M, Weltens I, Bervoets C, Fruyt J, Samochowiec J, Fiorillo A, et al. Tha pharmacological management of agitated and aggressive behaviour: A systematic review and metaanalysis. Eur Psychiatry. 2019;57:78-100

PMid:30721802

9. Dubovsky SL. Benzodiazepine reseptor agonists and antagonist. In: Sadock BJ, Sadock VA, Ruiz P, editors. Kaplan and Sadock's Comprehensive Textbook of Psychiatry. $10^{\text {th }}$ ed. Philadelphia, PA: Lippincott William and Wilkins; 2017. p. 7644-77. https://doi. org/10.4067/s0717-92272002000300011

10. Schleifer JJ. Management of acute agitation in psychosis: An evidance-based approach in USA. Adv Psychiatric Treatment. 2011;17:91-100. https://doi.org/10.1192/apt.bp.109.007310

11. CannonME,SprivulisP,McCartyJ.RestraintpracticesinAustralasian emergency departments. Aust N Z J Psychiatry. 2001;35(4):4647. https://doi.org/10.1046/j.1440-1614.2001.00925.x PMid:11531726

12. Magalhaes PV. A second look on intramuscular for psychiatric emergencies. Rev Psiq Clín. 2009;36(3):123. https://doi. org/10.1213/00000539-198301000-00001

13. Divoll M, Greenblatt DJ, Ochs HR, Shader RI. Absolute bioavailability of oral and intramuscular diazepam: Effect of age and sex. Anesth Analg. 1983;62(1):1-8. 


\section{PMid:6849499}

14. Priyatni N. Berapa kebutuhan diazepam untuk memenuhi pelayanan kesehatan di Indonesia? Studi kasus konsumsi diazepam di Indonesia. Prodi J Manajemen Pelayanan Farm. 2016;6(4):297-302. https://doi.org/10.22146/jmpf.359

15. Montoya A, Valladares A, Luis L, San L, Escobar R, Paz S. Validation of the excited component of the positive and negative syndrome scale (PANSS-EC) in a naturalistic sample of 278 patient with acute psychosis and agitation in a psychiatric emergency room. Health Qual Life Outcome. 2011;9:18. https:// doi.org/10.1186/1477-7525-9-18

PMid:21447155

16. Dahlan MS. Besar Sampel Dalam Penelitian Kedokteran dan Kesehatan. $4^{\text {th }}$ ed. Indonesia: Epidemiologi Indonesia; 2016. p. 194-201.

17. Bauer JO, Stenborg D, Lodahl T, Monsted MM. Treatment of agitation in the acute psychiatric setting. An observational study of the effectiveness of intramuscular psychotropic medication. Nord J Psychiatry. 2016;70(8):599-605. https://doi.org/10.1080/ 08039488.2016.1188982

PMid:27284637

18. Garriga M, Pacchiarotti I, Kasper S, Zeller SL, Allen $\mathrm{MH}$, Vázquez G, et al. Assessment and management of agitation in psychiatry: Expert consensus. World J Biol Psychiatry. 2016;17(2):86-128. PMid:26912127

19. Sim F, Sweetman I, Kapur S, Patel MX. Re-examining the role of benzodiazepines in the treatment of schizophrenia: A systematic review. J Psychopharmacol. 2015;29(2):212-23. https://doi.org/10.1177/0269881114541013 PMid:25049261

20. Zun LS. Evidence-based review of pharmacotherapy for acute agitation. Part 1: Onset of efficacy. J Emerg Med. 2018;54(3):364-74.

PMid:29361326

21. Dundar $\mathrm{Y}$, Greenhalgh J, Richardson M, Dwan K Pharmacological treatment of acute agitation associated with psychotic and bipolar disorder: A systematic review and metaanalysis. Hum. Psychopharmacol Clin Exp. 2016;31(4):268-85. https://doi.org/10.1002/hup.2535

PMid:27151529

22. Baron DA, Cobb RT, Juarez GM. Other psichiatric emergencies. In: Sadock BJ, Sadock VA, Ruiz P, editors. Kaplan and Sadock Comprehensive Textbook of Psychiatry. $10^{\text {th }}$ ed. Philadelphia,
PA: Lippincott William and Wilkins; 2017. p. 6696-736. https:// doi.org/10.4067/s0717-92272002000300011

23. Dahlan MS. Pintu Gerbang Memahami Statistik, Metodologi dan Epidemiologi. Sagung Seto: Epidemiologi Indonesia; 2014.

24. Dahlan MS. Statistik Untuk Kedokteran dan Kesehatan: Deskriptif, Bifariat dan Multivariat, Dilengkapi Aplikasi Menggunakan SPSS. $6^{\text {th }}$ ed. Indonesia: Epidemiologi Indonesia; 2015.

25. Pilowsky LS, Ring H, Shine PJ, Battersby M, Lader M. Rapid tranquillisation: A surveyof emergency prescribing in a general psychiatric hospital. Br J Psychiatry. 1992;160:831-5. https:// doi.org/10.1192/bjp.160.6.831

PMid:1352166

26. Strassnig MT, Harvey PD. First-generation antipsychotics. In: Sadock BJ, Sadock VA, Ruiz P, editors: Kaplan and Sadock Comprehensive Textbook of Psychiatry. $10^{\text {th }}$ ed. Philadelphia, PA: Lippincott William and Wilkins; 2017. p. 7817-73. https://doi. org/10.4067/s0717-92272002000300011

27. Sacchetti E, Amore M, Di Sciascio G, Ducci G, Girardi P, Mauri $\mathrm{M}$, et al. Psychomotor agitation in psychiatry: An Italian expert consensus. EB Psychiatric Care. 2017;3:1-24.

28. Chan EW, Tang C, Lao KS, Leung LP, Tsui MS, Ho HF, et al. Management of acute agitation in Hongkong and comparisons with Australasia. Emerg Med Australas. 2015;27(6):542-8. https://doi.org/10.1111/1742-6723.12499 PMid:26635127

29. Baldacara L, Sanches M, Cordeiro DC, Jackowski AP. Rapid tranquilization for agitated patients in emergency psychiatric room: A randomized trial of olanzapine, ziprasidone, haloperidol plus promethazine, haloperidol plus midazolam and haloperidol alone. Rev Bras Psiquiatria. 2011;33(1):30-9. https://doi. org/10.1590/s1516-44462011000100008

PMid:21537720

30. Huang $\mathrm{CL}$, Hwang TJ, Chen $\mathrm{YH}$, Huang $\mathrm{GH}$, Hsieh MH, Chen $\mathrm{HH}$ et al. Intramuscular olanzapine versus intramuscular haloperidol plus lorazepam for the treatment of acute schizophrenia with agitation: An open-label, randomized controlled trial. J Formos Med Assoc. 2015; 114(5):438-45. https://doi.org/10.1016/j. jfma.2015.01.018 PMid:25791540

31. Hatta K, Katayama S, Morikawa F, Imai A, Fujita K, Fujita A. A prospective naturalistic multicenter study on choice of parenteral medication in psychiatric emergency settings in Japan. Neuropsychopharmacol Rep. 2018;38:117-23. https:// doi.org/10.1002/npr2.12015 